\title{
Cytomegalovirus Infection and Inflammatory Bowel Disease
}

\section{Levent Filik}

Published online: 3 December 2009

(C) Springer Science+Business Media, LLC 2009

I read with great interest the recently published article by Maher and Nassar [1], which reports important outcomes related to cytomegalovirus (CMV) infection in inflammatory bowel disease (IBD). In the study, among 72 patients with active inflammatory bowel disease, 23 were resistant to steroids, and CMV was detected in 8 of the 23. The authors reported the cases as acute CMV infection and explained the absence of CMV IgM as a result of immunosuppression. Previous studies have reported that acute CMV colitis is very rare and most cases of CMV colitis in IBD are caused by reactivation of latent CMV infection [2, 3]. However, there were no CMV IgG data in that study to eliminate previous CMV infection. Also, there are some issues to be clarified in the study. There were no data for other viral serologic findings, for example, Epstein-Barr virus mimicking the symptoms of CMV. Were other bacterial pathogens such as C. difficile and E. hystolitica checked in the diagnosis algorithm as a common cause of bowel symptoms in IBD? Did all the patients diagnosed as having CMV take gancyclovir and respond well?

\section{References}

1. Maher MM, Nassar MI. Acute cytomegalovirus infection is a risk factor in refractory and complicated inlammatory bowel disease. Dig Dis Sci. 2009;54:2456-2462. doi:10.1007/s10620-008-0639-6.

2. Papadakis KA, Tung JK, Binder SW, et al. Outcome of cytomegalovirus infections in patients with inflammatory bowel disease. Am J Gastroenterol. 2001;96:2137-2142. doi:10.1111/j.1572-0241. 2001.03949.x.

3. Babyatsky MW, Keroack MD, Blake MA, et al. Case records of the Massachusetts general hospital. Case 35-2007. a 30 year old man with inflammatory bowel disease and recent onset of fever and bloody diarrhea. N Engl J Med. 2007;357:2068-2076.
L. Filik $(\bowtie)$

Gastroenterology Division, Ankara Research Hospital,

06600 Altindag, Ankara, Turkey

e-mail: leventfilik@yahoo.co.uk 